\title{
The natural history of Dandy-Walker syndrome in the United States: A population-based analysis
}

\author{
Shearwood McClelland $3^{\text {rdl }}$, Onyinyechi I. Ukwuoma², Scott Lunos ${ }^{3}$, Kolawole S. Okuyemi ${ }^{1,4}$ \\ ${ }^{1}$ Program in Health Disparities Research, ${ }^{4}$ Department of Family Medicine, University of Minnesota Medical School, ${ }^{3}$ Biostatistics Design \\ and Analysis Center, Clinical and Translational Science Institute, University of Minnesota, Minnesota, ${ }^{2}$ Department of Pediatrics, Brookdale \\ University Hospital and Medical Center, Brooklyn, New York, USA
}

\begin{abstract}
Background: Dandy-Walker syndrome (DWS) is a congenital disorder typically manifesting with hydrocephalus. The classic anatomic hallmarks of DWS are hypoplasia of the cerebellar vermis, anterior-posterior enlargement of the posterior fossa, upward displacement of the torcula and transverse sinuses, and cystic dilatation of the fourth ventricle. Aims: Although optimal treatment of DWS typically requires neurosurgical intervention to prevent intracranial pressure increases incompatible with life, the natural history of this disorder has yet to be evaluated on a nationwide level. Settings and Design/Materials and Methods: The Kids' Inpatient Database covering 1997-2003 was used for analysis. Children younger than age 18 admitted for DWS (ICD-9-CM $=742.3$ ) were analyzed with a matched control group. The primary procedure codes for operative CSF drainage were coded into the analysis. The incidence of DWS was $0.136 \% ; 14,599$ DWS patients were included. Statistical Analysis Used: Multiple logistic regression models were used. Odds ratios (OR) were reported with $95 \%$ confidence intervals. Results and Conclusions: Mortality $(\mathrm{OR}=10.02$; $P<0.0001)$ and adverse discharge disposition (OR $=4.59 ; P<0.0001)$ were significantly greater in DWS patients compared with controls. $20.4 \%$ of DWS patients received operative cerebrospinal fluid (CSF) drainage, 81 -times more than controls $(P<0.0001)$. CSF drainage reduced mortality by $44 \%$ among DWS patients $(P<0.0001)$. Although DWS is associated with a 10-fold increase in mortality, operative CSF drainage nearly halves the mortality rate. Based on these findings (Class IIB evidence), it is likely that the increased mortality associated with DWS is directly attributable to the nearly $80 \%$ of DWS patients who did not receive operative CSF drainage for hydrocephalus. Consequently, increased access to neurosurgical intervention could reduce the mortality rate of DWS towards that of the general population.
\end{abstract}

Key words: Cerebrospinal fluid, congenital hydrocephalus, Dandy-Walker syndrome, mortality

\section{Introduction}

Congenital hydrocephalus is a condition resulting from increased intracranial pressure in the ventricular system due to a derangement between the production and absorption of CSF. ${ }^{[1]}$ Classic clinical manifestations include bulging fontanelle, persistent downward gaze ("sun-setting" eyes), macrocephaly manifesting as rapidly increasing head circumference, irritability, vomiting, poor feeding, seizures, and lethargy. ${ }^{[2,3]}$ If

\begin{tabular}{|l|l|}
\hline \multicolumn{2}{|c|}{ Access this article online } \\
\hline Quick Response Code: & Website: \\
\hline & www.ruralneuropractice.com \\
\cline { 2 - 3 } & \\
\hline & DOI: \\
\hline
\end{tabular}

hydrocephalus is not addressed via neurosurgical intervention, the mortality of the condition is high due to the lethality of untreated increased intracranial pressure.

A well-known etiology of congenital hydrocephalus is Dandy-Walker syndrome (DWS), which encompasses Dandy-Walker malformation, Dandy-Walker variant, Blake pouch cyst, and mega cisterna magna. ${ }^{[4]}$ Classic anatomic hallmarks of DWS (also known as Dandy-Walker complex) are hypoplasia of the cerebellar vermis, anterior-posterior enlargement of the posterior fossa, upward displacement of the torcula and transverse sinuses, and cystic dilatation of the fourth ventricle. ${ }^{[5]}$ With an incidence of approximately 1 in 30,000, the clinical manifestations of hydrocephalus in DWS are diagnosed prior to the age of one in $80 \%$ of patients. ${ }^{[6-8]}$ However to date, there has been no examination of the natural history of DWS on a nationwide level. This study was performed to address this void.

\section{Address for correspondence:}

Dr. Shearwood McClelland $3^{\text {rd }}$, Program in Health Disparities Research, University of Minnesota, 717 Delaware St SE, Suite 166, Minneapolis, Minnesota - 55414, USA. E-mail: drwood@post.harvard.edu 


\section{Materials and Methods}

\section{Data source}

The data source for this study was the Kids' Inpatient Database (KID) hospital discharge database (overview available at http://www.hcup-us.ahrq.gov/ kidoverview.jsp) covering the years 1997 through 2003. Containing data drawn from children 20 years of age and younger, the KID was obtained from Healthcare Cost and Utilization Project, Agency for Healthcare Research and Quality (Rockville, MD). ${ }^{[9]}$ For these years, the KID contains data on $100 \%$ of discharges from a stratified random sample of nonfederal hospitals in 22 to 36 states (number of states increased year to year from 1997 to 2003), containing data on two to three million hospital discharges from a sample of 2500 to 3500 United States nonfederal hospitals.

\section{Inclusion and exclusion criteria}

The KID database was searched to identify an admission for DWS. Admissions having a patient age younger than 18 years and a diagnosis code of 742.3 (Dandy-Walker deformity or syndrome) were included. Using the same database, admissions younger than 18 years without the diagnosis code of 742.3 were included as a control group.

\section{Characteristics of patients, providers, and hospitals}

In addition to race, patient age, sex, median household income for postal (ZIP) code of residence, primary payer (Medicare, Medicaid, private insurance, self-pay, no charge, or other), type of admission (emergency, urgent, or elective), and admission source (emergency department, transfer from another hospital, transfer from long-term care, or routine) were coded in the KID data. The number of available beds (small, medium, large), teaching status, hospital region (Northeast, Midwest, South, West), and location (rural, urban) were coded in the KID data. Furthermore, the primary procedure codes for operative CSF drainage $(02.2,02.31,02.32,02.33,02.34,02.35,02.39$, $03.71,03.72,03.79)$ were coded as well.

\section{Statistical analysis}

The characteristics of patients (inpatient stays) and hospitals were summarized by descriptive statistics. Results were presented for continuous variables (mean, $\mathrm{SD}$, median, and range) and frequency (percentage) for categorical variables. Patients admitted with DWS (ICD-9-CM = 742.3) were included for primary analysis, and a matched control group of patients without a DWS diagnosis was used for comparison of the outcomes. Groups were matched for patient age, gender, race, primary payer, caseload of hospital, admission type, and income within each survey year. To compare the outcomes of mortality, operative CSF drainage, and adverse discharge disposition between the groups we used simple logistic regression models. To examine the association between mortality and the characteristics of patient age, gender, race, payer, admission type, income, and caseload of hospital in the DWS group, we fitted multiple logistic regression models using the aforementioned characteristics as covariates. We reported odds ratios (ORs) with $95 \%$ confidence intervals (CIs). Extrapolations to the entire U.S. population were adjusted for the NIS stratified survey method in the logistic regression models by using PROC SURVEYLOGISTIC in SAS version 9.3 (SAS Institute, Cary, NC). All $P$ values shown are 2-tailed. A $P$ value less than 0.05 was deemed statistically significant. Patients were evaluated examining DWS (a) as a primary diagnosis, (b) as one of the top 3 diagnoses, and (c) as one of the top 15 diagnoses. Adverse discharge disposition was defined as hospital discharge to any place other than home (i.e. short-term rehabilitation, long-term rehabilitation, hospice, etc.).

\section{Results}

The KID database contained 14,599 DWS patients between 1997 and 2003, with an overall incidence of 1.36 per 1,000 children. The DWS and control groups were matched for age, gender, race, primary payer, caseload, admission type, and income; the control group consisted of 14,508 patients [Table 1]. The mortality rate was $3.77 \%$ in the DWS group compared with $0.39 \%$ in the control group (OR $=10.02 ; P<0.0001)$ [Table $2 \mathrm{a}$ and $\mathrm{b}$ ]. CSF drainage procedures occurred in $20.39 \%$ of DWS patients compared with only $0.31 \%$ of controls $(\mathrm{OR}=81.11$; $P<0.0001$ ) [Table 2a and b]. Adverse discharge disposition occurred in $10.92 \%$ of DWS patients versus $2.6 \%$ of controls $(\mathrm{OR}=4.59 ; P<0.0001)$ [Table $2 \mathrm{a}$ and $\mathrm{b}$ ].

CSF drainage was required in $20.39 \%$ of the DWS group compared with $0.31 \%$ of controls [Table 2a]. Among DWS patients, CSF drainage independently predicted significantly reduced mortality $(\mathrm{OR}=0.56 ; \mathrm{CI}=0.42-0.74$; $P<0.0001)$ and adverse discharge disposition $(\mathrm{OR}=0.72$; $\mathrm{CI}=0.58-0.91 ; P=0.0052)$ compared with patients unable to receive CSF drainage [Table 3]. Consequently, DWS patients were $44 \%$ less likely to die and $28 \%$ less likely to have an adverse discharge disposition if they received CSF drainage [Table 3].

\section{Discussion}

Examination of the natural history of DWS has not previously been performed on a nationwide level. 
Table 1: Clinical characteristics of patients (inpatient stays) with a diagnosis of Dandy-Walker syndrome and a matched control group

\begin{tabular}{|c|c|c|}
\hline Characteristic & $\begin{array}{l}\text { DWS group } \\
(N=14,599)\end{array}$ & $\begin{array}{c}\text { Control group } \\
(N=14,508)\end{array}$ \\
\hline \multicolumn{3}{|l|}{ Age (years) } \\
\hline Mean & 3.2 & 3.2 \\
\hline Standard deviation & 4.6 & 4.6 \\
\hline Median & 1.0 & 1.0 \\
\hline Min-Max & $0-17$ & $0-17$ \\
\hline Female (\%) & 43.6 & 43.6 \\
\hline \multicolumn{3}{|l|}{ Race (\%) } \\
\hline White & 51.3 & 51.7 \\
\hline African American & 18.9 & 18.9 \\
\hline Hispanic & 21.2 & 21.2 \\
\hline Asian/Pacific Islander & 2.6 & 2.6 \\
\hline Other & 5.9 & 5.7 \\
\hline \multicolumn{3}{|l|}{ Primary payer (\%) } \\
\hline Medicare & 0.1 & 0.1 \\
\hline Medicaid & 48.4 & 48.6 \\
\hline Private insurance/HMO & 44.9 & 45.0 \\
\hline Self-pay & 2.4 & 2.3 \\
\hline No charge/other & 4.3 & 4.0 \\
\hline \multicolumn{3}{|l|}{ Caseload of hospital (\%) } \\
\hline Small bed size & 14.9 & 14.7 \\
\hline Medium bed size & 25.4 & 25.4 \\
\hline Large bed size & 59.8 & 59.9 \\
\hline \multicolumn{3}{|l|}{ Geographic region of hospital (\%) } \\
\hline Northeast & 25.2 & 22.7 \\
\hline Midwest & 16.5 & 16.2 \\
\hline South & 28.4 & 32.4 \\
\hline West & 29.9 & 28.7 \\
\hline \multicolumn{3}{|l|}{ Location of hospital (\%) } \\
\hline Urban & 96.8 & 88.9 \\
\hline Rural & 3.2 & 11.1 \\
\hline \multicolumn{3}{|l|}{ Admission type (\%) } \\
\hline Emergency & 39.5 & 39.6 \\
\hline Urgent & 20.4 & 20.4 \\
\hline Elective & 20.2 & 20.1 \\
\hline Newborn & 19.9 & 20.0 \\
\hline Other & 0.02 & 0.01 \\
\hline \multicolumn{3}{|l|}{ Admission source (\%) } \\
\hline Routine, birth, others & 53.7 & 57.6 \\
\hline Emergency/other/facility/court/law & 46.3 & 42.4 \\
\hline \multicolumn{3}{|l|}{ Median income $(\$)$} \\
\hline $1=1-24,999$ & 49.4 & 49.3 \\
\hline $2=25,00-34,999$ & 21.1 & 21.1 \\
\hline $3=35,000$ and above & 29.6 & 29.6 \\
\hline
\end{tabular}

Table 2a: Incidence of mortality, cerebrospinal fluid drainage, and adverse discharge disposition in DWS and control groups

\begin{tabular}{lcc}
\hline Outcome (\%) & DWS group & Control group \\
\hline Mortality & 3.77 & 0.39 \\
CSF drainage & 20.39 & 0.31 \\
Adverse discharge disposition & 10.92 & 2.60 \\
\hline
\end{tabular}

CSF: Cerebrospinal fluid, DWS: Dandy-Walker syndrome
Using a nationwide pediatric database encompassing a seven-year period, the natural history of DWS was examined, yielding an incidence of $0.136 \%$. A comparison with a matched control group revealed a greater than 81-fold increase in intraoperative CSF draining procedures, a nearly 5 -fold increase in adverse discharge disposition, and a 10-fold increased mortality in the DWS group [Table 2]. However, DWS patients who underwent intraoperative CSF drainage had a $44 \%$ lower mortality $(P<0.0001)$ than those who did not undergo CSF drainage [Table 3]. Consequently, it is reasonable to surmise that the increased mortality associated with DWS is directly attributable to the proportion of DWS patients who did not undergo operative CSF drainage for hydrocephalus (which in this study was nearly $80 \%$ of patients), and that increased access to neurosurgical intervention could have decreased the mortality rate of DWS to that similar to the control group.

As important as these results are, they should be tempered by the limitations of this study. The primary limitation is the retrospective nature of the study, which necessitated the use of odds ratios instead of relative risk for statistical interpretation of the data. Secondly, the KID by its nature is incomplete in representing the United States; although it is by far the most comprehensive nationwide database available spanning 1997-2003, it only includes a maximum of 36 of the 50 US states, and does not include federal hospitals. Another limitation is that the ICD-9 code does not allow for distinguishing between the different components of DWS; consequently, there is no way from this study to distinguish between Dandy-Walker variant from Dandy-Walker malformation, Blake pouch cyst, and mega cisterna magna, all of which comprise DWS. Furthermore, although the ICD-9 code of 742.3 corresponds to Dandy-Walker variant, this code also corresponds to congenital hydrocephalus, which introduces the possibility that hydrocephalus from etiologies other than DWS (i.e. posthemorrhagic, aqueductal stenosis, Chiari malformation, intrauterine infection, arachnoid cysts, etc.) could have been included in this study. Unfortunately, this is probably the greatest limitation of our manuscript, as the incidence of DWS we found of $0.136 \%$ was approximately 40 times higher than the established incidence of DWS $(1 / 30,000=0.0033 \%)$, indicating that a significant portion of the DWS group had hydrocephalus (more than would be expected from a population derived solely from DWS patients). Supporting this hypothesis is the fact that our DWS incidence of $0.136 \%$ is similar to the $0.114 \%$ incidence recently reported in a Denmark study examining that country's nationwide incidence of primary congenital hydrocephalus. ${ }^{[10]}$ Finally, the time span of this study encompassed a period 
Table 2b: Univariate analysis of mortality, CSF drainage, and adverse discharge disposition between groups (the control is the reference group)

\begin{tabular}{lcc}
\hline Outcome & OR $(95 \% \mathrm{Cl})$ & $\boldsymbol{P}$ value \\
\hline Mortality & $10.02(7.80-12.85)$ & $<0.0001$ \\
CSF drainage & $81.11(61.15-107.58)$ & $<0.0001$ \\
Adverse discharge disposition & $4.59(4.01-5.27)$ & $<0.0001$ \\
\hline
\end{tabular}

CSF: Cerebrospinal fluid, OR: Odds ratio, Cl: Confidence interval

Table 3: Analysis of CSF Drainage versus no CSF drainage among DWS patients

\begin{tabular}{lcc}
\hline Outcome & OR $(95 \% \mathrm{Cl})$ & $\boldsymbol{P}$ value \\
\hline Mortality & $0.56(0.42-0.74)$ & $<0.0001$ \\
Adverse discharge disposition & $0.72(0.58-0.91)$ & 0.0052 \\
\hline
\end{tabular}

CSF: Cerebrospinal fluid, OR: Odds ratio, Cl: Confidence interval

where ventriculoperitoneal shunting was the only widely recognized surgical treatment for congenital hydrocephalus. With the recent popularization of endoscopic third ventriculostomy (ETV) by the work of Dr. Benjamin Warf in Uganda from 2004 to 2010, the potential for treatment of congenital hydrocephalus secondary to DWS has become even greater, as more patients may be able to receive life-saving treatment without becoming shunt dependent. ${ }^{[4]}$ This additional surgical treatment option may improve quality of life and reduce the mortality of DWS not only in the United States, but worldwide as well.

Despite these limitations, the novel use of the KID in this study over a 7-year period allows for the most definitive depiction of the natural history of DWS to-date, and by proxy, congenital hydrocephalus as well. The population-based nature and breadth of the KID allows the results from this study to provide class IIB evidence, and should reaffirm the necessity for children with DWS to be referred for neurosurgical care early in the course of the disease.

\section{References}

1. Fishman MA. Developmental defects. In: McMillan JA, DeAngelis CD, Feigin RD, Warshaw JB, editors. Oski's Pediatrics: Principles and Practice. $3^{\text {rd }}$ ed. Philadelphia, PA: Lippincott Williams and Wilkins; 1999. p. 1906-9.

2. Boragina M, Cohen E. An infant with the "setting-sun" eye phenomenon. CMAJ 2006;175:878.

3. Tzekov C, Cherninkova S, Gudeva T. Neuroophthalmological symptoms in children treated for internal hydrocephalus. Pediatr Neurosurg 1991-1992;17:317-20.

4. Warf BC, Dewan M, Mugamba J. Management of Dandy-Walker complex-associated infant hydrocephalus by combined endoscopic third ventriculostomy and choroid plexus cauterization. J Neurosurg Pediatr 2011;8:377-83.

5. Klein O, Pierre-Kahn A, Boddaert N, Parisot D, Brunelle F. Dandy-Walker malformation: Prenatal diagnosis and prognosis. Childs Nerv Syst 2003;19:484-9.

6. Menkes JH, Sarnat HB. Neuroembryology, genetic programming, and malformations. In: Menkes JH, Sarnat HB, editors. Child Neurology. $6^{\text {th }}$ ed. Philadelphia, PA: Lippincott Williams and Wilkins; 2000. p. 354-77.

7. Ashwal S. Congenital structural defects. In: Swaiman KF, Ashwal S, editors. Pediatric Neurology: Principles and Practice. $3^{\text {rd }}$ ed. St. Louis: Mosby; 1999. p. 266-73.

8. Pascual-Castroviejo I, Velez A, Pascual-Pascual SI, Roche MC, Villarejo F. Dandy-Walker malformation: Analysis of 38 cases. Childs Nerv Syst 1991;7:88-97.

9. Steiner C, Elixhauser A, Schnaier J. The healthcare cost and utilization project: An overview. Eff Clin Pract 2002;5:143-51.

10. Munch TN, Rostgaard K, Rasmussen ML, Wohlfahrt J, Juhler M, Melbye M. Familial aggregation of congenital hydrocephalus in a nationwide cohort. Brain 2012;135:2409-15.

How to cite this article: McClelland S, Ukwuoma OI, Lunos S, Okuyemi KS. The natural history of Dandy-Walker syndrome in the United States: A population-based analysis. J Neurosci Rural Pract 2015;6:23-6.

Source of Support: Nil. Conflict of Interest: None declared.

\section{New features on the journal's website}

\section{Optimized content for mobile and hand-held devices}

HTML pages have been optimized of mobile and other hand-held devices (such as iPad, Kindle, iPod) for faster browsing speed.

Click on [Mobile Full text] from Table of Contents page.

This is simple HTML version for faster download on mobiles (if viewed on desktop, it will be automatically redirected to full HTML version)

\section{E-Pub for hand-held devices}

EPUB is an open e-book standard recommended by The International Digital Publishing Forum which is designed for reflowable content i.e. the text display can be optimized for a particular display device.

Click on [EPub] from Table of Contents page.

There are various e-Pub readers such as for Windows: Digital Editions, OS X: Calibre/Bookworm, iPhone/iPod Touch/iPad: Stanza, and Linux: Calibre/Bookworm.

\section{E-Book for desktop}

One can also see the entire issue as printed here in a 'flip book' version on desktops.

Links are available from Current Issue as well as Archives pages.

Click on View as eBook 